\title{
Maximal left ventricular wall thickness: a comparison between CMR and echocardiography in hypertrophic cardiomyopathy
}

\author{
Celia P Corona-Villalobos ${ }^{1 *}$, Lars Sorensen², Linda Chu', Theodore Abraham², Ihab R Kamel', Stefan L Zimmerman \\ From 16th Annual SCMR Scientific Sessions \\ San Francisco, CA, USA. 31 January - 3 February 2013
}

\section{Background}

Echocardiography (ECHO) is used for diagnosis and management of hypertrophic cardiomyopathy (HCM). Morphologic diagnosis is based on the presence of myocardial thickness of $>15 \mathrm{~mm}$ in adults or a septum to posterior wall ratio of $>1.5$. Septal wall thickness (WT) $>30 \mathrm{~mm}$ is one of several high risk features that are used to guide the decision for prophylactic implantable cardioverter-defibrillator (ICD) placement. Cardiac magnetic resonance imaging (CMR) offers improved contrast resolution over ECHO and precisely defines myocardial WT in HCM.CMR is used in suspected $\mathrm{HCM}$ when ECHO is inconclusive for diagnosis or when additional information is needed.

We tested the hypothesis that there are differences in maximal left ventricular myocardial WT as measured by CMR and ECHO in subjects with HCM due to asymmetric septal hypertrophy (ASH).

\section{Methods}

64 subjects with $\mathrm{HCM}$ and ASH pattern (mean age 51 years, range 18-88 years), underwent $\mathrm{ECHO}$ and CMR within the same day. Maximal WT by ECHO was measured on parasternal long axis view in the anteroseptal and the basilar posterior wall. WT by CMR was measured on the short axis view manually to obtain maximal dimensions in the same segments as those obtained by ECHO.

\section{Results}

Overall, mean maximal septal WT for all patients was less by CMR compared with ECHO, but not statistically

'Radiology and Radiological Science, Johns Hopkins Hospital, Baltimore, MD, USA

Full list of author information is available at the end of the article significant $(19.1+4.7$ and $20.5+4.4$, respectively, $\mathrm{p}>.05)$. We stratified our population into two groups by maximal septal WT: A) $>15-19.9 \mathrm{~mm}$ and B) $>20 \mathrm{~mm}$. CMR showed less mean maximal septal WT than ECHO, which was significant only in group B [group A (16.8 +3.6 and $17.1+1.5$, respectively, $p>05$ ) and group $B$ $(21.8+4.4$ and $24.7+3.1$, respectively, $\mathrm{p}<.05)]$. The posterior wall showed greater WT for CMR compared with $\mathrm{ECHO}$, which was significant only in group B [group A $(12.3+2.7$ and $11.1+2.7, \mathrm{p}>.05)$ and $\mathrm{B}(13.7+3.8$ and 11.8 +2.6 , respectively, $\mathrm{p}<.05)$ ]. On a per patient basis, the difference between ECHO and CMR for maximal septal WT was greatest in group B but significant $(p<0.05)$ for both groups (group A $-0.3+3.6 \mathrm{~mm}$ and group B -2.9 $+3.9 \mathrm{~mm}$ ). On per patient basis, the difference between $\mathrm{ECHO}$ and CMR for the posterior wall was greater but significant only in group B (group A 1.2+3.1, p >.05 and $1.8+4.2 \mathrm{~mm}, \mathrm{p}<.05)$. The septal to posterior wall ratio calculated by CMR and ECHO was also significantly different (Group A 1.4+0.4 and 1.6+0.4 and Group B 1.7 +2.2 and $2.2+0.5$ respectively, $\mathrm{p}<.05$ ). ECHO and CMR showed good correlation for the septal WT $(r=.62$, $\mathrm{p}<.001$ ); however there was a poor correlation for the posterior wall $(\mathrm{r}=.36, \mathrm{p}<.001)$.

\section{Conclusions}

In subjects with WT $>20 \mathrm{~mm}$ echocardiography shows systematically higher septal WT and lower posterior WT resulting in higher septal to posterior wall ratio compared to CMR. These findings have potential clinical implications for diagnosis and management of subjects with HCM.

\section{Funding}

No funding was given for this project. 

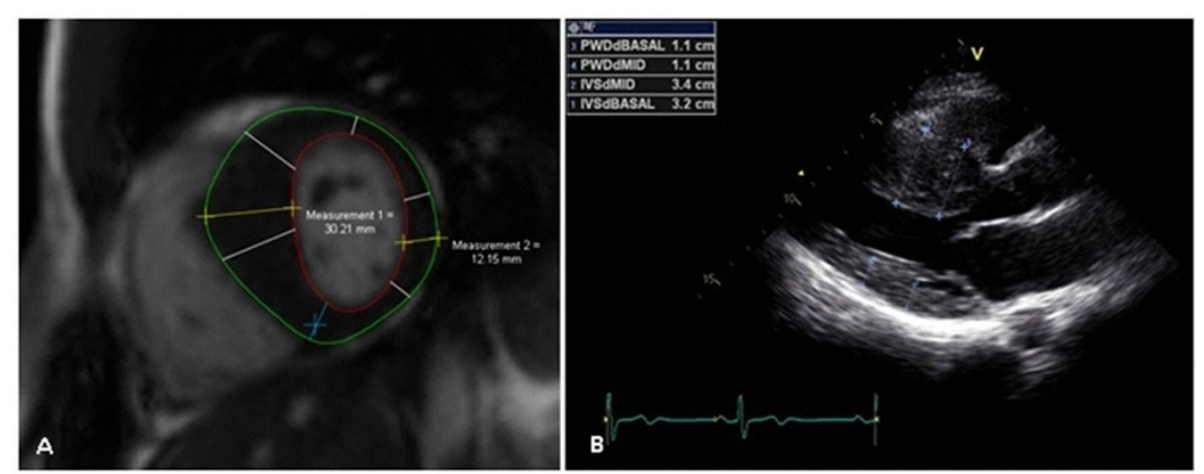

Figure 1 Maximal wall thickness measures in end diastolic phase by a) CMR and by b) ECHO at the basilar septum and posterior wall.

Table 1 Demographics and myocardial wall thickness in our cohort stratified into two groups

\begin{tabular}{|c|c|c|}
\hline & Wall thickness $15-19.9 \mathrm{~mm}(\mathrm{n}=35)$ & Wall thickness $\geq 20 \mathrm{~mm}(\mathrm{n}=29)$ \\
\hline Demographics Age (years) BSA (m2) Gender Males Female & $\begin{array}{c}47.1+15.72 .1+0.423(66 \%) \\
(34 \%)\end{array}$ & $53.7+15.4 \underset{(24 \%)}{2.1+0.322(76 \%) 7}$ \\
\hline $\begin{array}{c}\text { Maximal Septal Wall Thickness (mm) MRI Echo Per patient difference (MRI - } \\
\text { Echo) }\end{array}$ & $16.8+3.617 .1+1.5-0.3+3.6$ & $21.8+4.424 .7+3.1-2.9+3.9$ \\
\hline $\begin{array}{c}\text { Maximal Posterior Wall Thickness (mm) MRI Echo Per patient difference (MRI - } \\
\text { Echo) }\end{array}$ & $12.3+2.711 .1+2.71 .2+3.1$ & $13.7+3.811 .8+2.61 .8+4.2$ \\
\hline Septum to Posterior Wall Ratio MRI Echo Per patient difference (MRI - Echo) & $1.4+0.41 .6+0.4-0.2+0.6$ & $1.7+0.62 .2+0.5-0.5+0.6$ \\
\hline
\end{tabular}

Values are reported as mean + standard deviation unless state otherwise.

\section{Author details}

'Radiology and Radiological Science, Johns Hopkins Hospital, Baltimore, MD,

USA. ${ }^{2}$ Department of Cardiology, Johns Hopkins Hospital, Baltimore, MD,

USA.

Published: 30 January 2013

doi:10.1186/1532-429X-15-S1-P169

Cite this article as: Corona-Villalobos et al: Maximal left ventricular wall

thickness: a comparison between CMR and echocardiography in

hypertrophic cardiomyopathy. Journal of Cardiovascular Magnetic

Resonance 2013 15(Suppl 1):P169.

\section{Submit your next manuscript to BioMed Central} and take full advantage of:

- Convenient online submission

- Thorough peer review

- No space constraints or color figure charges

- Immediate publication on acceptance

- Inclusion in PubMed, CAS, Scopus and Google Scholar

- Research which is freely available for redistribution 